\title{
Correction: Paediatric Horner's syndrome: is investigation for underlying malignancy always required?
}

Braungart S, Craigie R J, Farrelly P, et al. Paediatric Horner's syndrome: is investigation for underlying malignancy always required? (Arch Dis Child 2019;104:984-7).

During the production process the citation numbers in table 3 were incorrectly inserted. They should be as follows: Sauer $e t a l^{8}$, Woodruff et $a l^{9}$, Jeffery et $a l^{10}$, George $e t a l^{11}$, Mahoney et $a l^{12}$, Smith et $a l^{13}$, Kadom et $a l^{14}$, Martin et $a l^{17}$.

(C) Author(s) (or their employer(s)) 2020. No commercial re-use. See rights and permissions. Published by BMJ.

Arch Dis Child 2020;105:e4. doi:10.1136/archdischild-2019-317007corr1

D) Check for updates 